\title{
Relation of high neuroticism with increased methylation of the BDNF gene
}

This article was published in the following Dove Press journal:

Neuropsychiatric Disease and Treatment

\author{
Toshinori Shirata' \\ Akihito Suzuki' \\ Yoshihiko Matsumoto' \\ Nana Takahashi' \\ Keisuke Noto' \\ Kaoru Goto ${ }^{2}$ \\ Koichi Otani' \\ 'Department of Psychiatry, Yamagata \\ University School of Medicine, \\ Yamagata, Japan; ${ }^{2}$ Department of \\ Anatomy and Cell Biology, Yamagata \\ University School of Medicine, \\ Yamagata, Japan
}

\begin{abstract}
Background: Brain-derived neurotrophic factor (BDNF) is a neurotrophin that has an important function in neuroplasticity and neuronal development. It is suggested that increased methylation of the BDNF gene resulting in decreased BDNF activity is associated with depression. Meanwhile, neuroticism is a well-known risk factor for developing depression. In the present study, the relationship between methylation of the BDNF gene and personality traits including neuroticism was examined.
\end{abstract}

Subjects and methods: The subjects were 98 healthy Japanese. Methylation levels of the BDNF gene were determined by the bisulfite-pyrosequencing method. Personality traits including neuroticism were assessed by the NEO Personality Inventory-Revised.

Results: There was a positive correlation between neuroticism scores and methylation levels of the BDNF gene. The subjects with higher neuroticism scores had higher levels of BDNF gene methylation compared with those with lower neuroticism scores. Meanwhile, other personality traits were not associated with BDNF gene methylation.

Conclusion: The present study suggests that high neuroticism is related to increased methylation of the BDNF gene.

Keywords: BDNF, depression, epigenetics, methylation, neuroticism

\section{Introduction}

Epigenetics is defined as heritable changes in gene activity and expression that occur without alteration in DNA sequence. ${ }^{1}$ These non-genetic alternations are regulated by two major mechanisms, ie, DNA methylation and histone modification. ${ }^{2}$ DNA methylation occurs through the addition of a methyl group to cytosines mainly at the cytosine-guanine dinucleotides (CG sites). In mice and humans, most of the CG sites in the promoter regions exist mostly in an unmethylated form. ${ }^{2}$ When these CG sites are methylated, the onset of transcription and gene expression is prevented. ${ }^{1}$

Brain-derived neurotrophic factor (BDNF) is a member of the neurotrophin family that serves an important function in neural differentiation, survival of nerve cells and synaptic plasticity. ${ }^{3,4}$ In BDNF transgenic mice, decreased BDNF activity is associated with reduced hippocampal volume and increased anxiety-related behaviors. ${ }^{4}$ In humans, decreased BDNF activity is related to small hippocampal volume and poor hippocampal-dependent learning. ${ }^{3,5}$ A meta-analysis shows that low blood levels of BDNF are associated with psychiatric disorders such as depression. ${ }^{6}$ Meanwhile, recent epigenetic studies demonstrate that increased methylation of the BDNF gene causes decreased BDNF synthesis in neurons. ${ }^{7}$ Furthermore, an extensive review suggests that BDNF gene methylation is increased in depressed patients compared to controls. ${ }^{8}$ These findings suggest that increased methylation of the BDNF gene resulting in
Correspondence: Akihito Suzuki Department of Psychiatry, Yamagata University School of Medicine, 2-2-2 lida-Nishi, Yamagata 990-9585, Japan Tel +8I 236285322

Fax +81236285325

Email suzukiakihito@hotmail.com
Neuropsychiatric Disease and Treatment 2018:14 1787-1793

(c) (1) (8) () 2018 Shirata et al. This work is published and licensed by Dove Medical Press Limited. The full terms of this license are avalable at https://www.dovepress.com/terms.php cc) hereby accept the Terms. Non-commercial uses of the work are permitted without any further permission from Dove Medical Press Limited, provided the work is properly attributed. For peminsion for commercial use of this work, please see paragraphs 4.2 and 5 of our Terms (htpps://www.dovepress. com/terms.php). 
decreased BDNF activity is at least partly implicated in the pathogenesis of depression.

Neuroticism is a tendency to cope poorly with stress and to experience negative effects such as fear, sadness, embarrassment, anger, guilt and disgust. ${ }^{9}$ This personality trait constitutes one of the five factors in the Big Five model of personality. ${ }^{9}$ The other four personality traits are extraversion (a tendency to engage the environment and other people with vigor and enthusiasm), openness to experience (a tendency to be broad, deep and complex in mental and experiential life), agreeableness (a tendency to be altruistic and sympathetic to others and eager to help them) and conscientiousness (a tendency to approach tasks in a planful and deliberate manner and to be reliable and selfdisciplined). Extensive reviews strongly suggest that high neuroticism is a prospective predictor of clinical depression in general populations. ${ }^{10,11}$ A complex interaction between this personality trait and life stressors, ie, the diathesis-stress mechanism, is involved in the process from high neuroticism to the development of depression. Additionally, one study suggests that low extraversion carries the risk for new-onset depression, though to a lesser degree than high neuroticism. ${ }^{12}$ Furthermore, a possibility is pointed out that low extraversion and low conscientiousness, by interacting with high neuroticism, also contribute to the onset of depression. ${ }^{10}$

As mentioned previously, each of increased BDNF gene methylation and neuroticism has been reported to be closely associated with depression. Furthermore, our previous study suggests that decreased BDNF function is related to high harm avoidance and low self-directedness, personality traits connected with neuroticism. ${ }^{13}$ It is also demonstrated that lower serum BDNF levels are inversely related to neuroticism. ${ }^{14}$ These findings point to the possibility that neuroticism is related to increased methylation of the BDNF gene. Therefore, we examined the relationship between methylation levels of the BDNF gene and personality traits including neuroticism.

\section{Subjects and methods Subjects}

The subjects were 98 Japanese medical students from Yamagata University School of Medicine. The exclusion criteria were the presence of serious physical diseases and current or past Axis I psychiatric disorders of the Diagnostic and Statistical Manual of Mental Disorders-IV. ${ }^{15}$ As it is reported that BDNF gene methylation and some personality traits are influenced by age, ${ }^{16,17}$ the subjects in a narrow age range (22-23 years old) were enrolled. Males and females were equal in number. The mean $\pm \mathrm{SD}$ of body mass index (BMI) was $21.0 \pm 2.5 \mathrm{~kg} / \mathrm{m}^{2}$. The Ethics Committee of Yamagata University School of Medicine approved the protocol of this study. After complete explanation of the study, written informed consent was obtained from all subjects.

\section{Assessment of personality traits}

Assessment of personality traits was performed using the Japanese version of the NEO Personality Inventory-Revised (NEO PI-R). ${ }^{9} 18$ This Japanese version has high reliability and validity. ${ }^{18}$ The NEO PI-R is a self-report scale with five subscales to measure the Big Five personality traits, ie, neuroticism, extraversion, openness to experience, agreeableness and conscientiousness. ${ }^{9}$ Each subscale is composed of 48 items, resulting in total of 240 items. Respondents rate how true the items are about themselves on a Likert scale ranging from 1 (strongly disagree) to 5 (strongly agree).

\section{Analysis of BDNF gene methylation}

Ten milliliters of blood was obtained from subjects' median vein in a EDTA-containing tube. Genomic DNA was extracted from peripheral leukocytes using a QIAamp DNA Blood Kit (Qiagen, Tokyo, Japan). DNA concentrations were measured using a Qubit dsDNA BR Assay Kits (Thermo Fisher Scientific K.K., Tokyo, Japan), and genomic DNA was stored at $-80^{\circ} \mathrm{C}$ until analysis. Martinowich et al showed that the promoter IV region of the BDNF gene has the cAMP response element-binding protein (CREB)-binding site and that the methylation of this region affects CREB binding and consequent transcription. ${ }^{7}$ Meanwhile, Kundakovic et al showed that in mice the administration of bisphenol A, a model of early life adversity, induces increased methylation of the two CG sites in this region and reduces BDNF expression. ${ }^{19}$ They also demonstrated that methylation of these CG sites is increased in pregnant mothers with higher urine levels of bisphenol A. Therefore, we measured methylation levels of these CG sites in the present study.

Pyrosequencing analysis of bisulfite-converted genomic DNA was performed by EpigenDx Inc. (Worcester, MA, USA), with the assay ID ADS221-FS2re and ADS221-FS3. The examined region of the promoter IV of the BDNF gene is located on the coordinates Chr11: 27723159-27723246 (University of California, Santa Cruz Genome Browser, Human February 2009, GRCh37/hg19) (Figure 1). The methylation status of each CG sites was determined individually as an artificial C/T SNP using QCpG software (Pyrosequencing, Qiagen). Methylation levels of each CG site were calculated as the percentage of the methylated alleles divided by the sum 


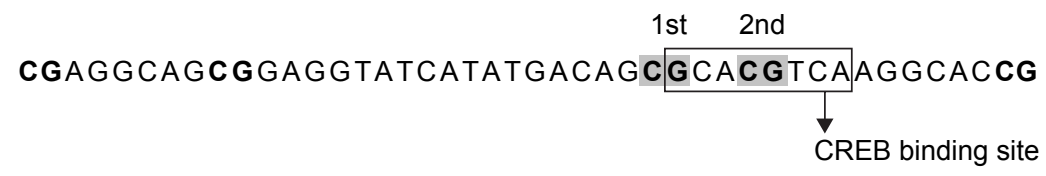

TGGAGCCCTCTCGTGGACTCCCACCCACTTTCCCCATTCACCGCG

$\longrightarrow$ Exon IV

Figure I The CG sites analyzed in the promoter IV region of the BDNF gene.

Notes: The presented genomic region is Chrl I: 27723I59-27723246 (University of California, Santa Cruz Genome Browser, Human February 2009, GRCh37/hgI9). Bold characters indicate the CG sites in the examined region.

Abbreviations: BDNF, brain-derived neurotrophic factor; CREB, cAMP response element-binding protein.

of all methylated and unmethylated alleles. Mean methylation levels were calculated using methylation levels of two CG sites within the examined region of the BDNF gene.

\section{Statistical analyses}

One study showed an interaction effect between sex and early life adversity on BDNF gene methylation. ${ }^{19}$ Meanwhile, in our previous study, increased BMI was associated with high harm avoidance and low self-directedness, personality traits closely related to neuroticism. ${ }^{20}$ Therefore, sex and BMI were included in statistical analyses. The correlations among NEO PI-R scores, BMI and BDNF methylation levels were tested by the Pearson's linear regression test. The effects of the NEO PI-R scores and sex on methylation levels of the BDNF gene were analyzed by the two-way analysis of covariance with BMI as a covariate. In each of the five domains of the NEO PI-R, a score equal to or lower than the median was regarded as low and the others were regarded as high. All statistical analyses were performed by the Statistical Package for Social Sciences (SPSS) version 22 (IBM corporation, Armonk, NY, USA). A $p$-value of $<0.05$ (two-tailed) was regarded as significant.

\section{Results}

Demographic characteristics, five domain scores of the NEO PI-R and methylation levels of the BDNF gene of the subjects are shown in Table 1.

Table 2 shows Pearson's correlations among NEO PI-R scores, BMI and BDNF gene methylation levels. There was a positive correlation $(p<0.05)$ between neuroticism scores and methylation levels of the 1st CG site (Table 2 and Figure 2).

The results of the two-way analysis of covariance are shown in Table 3. The subjects with higher neuroticism scores had higher levels of 1 st CG site methylation $(p<0.01)$ and higher mean levels of 1 st and 2nd CG site methylation $(p<0.05)$ compared with those with lower neuroticism scores. Pyrograms of representative individuals with high and low neuroticism scores are shown in Figure 3. Scores of extraversion, openness to experience, agreeableness and conscientiousness were not associated with methylation levels of the BDNF gene. There was no main effect of sex or interaction effects between NEO PI-R scores and sex on BDNF gene methylation levels.

When the correlations of personality traits with methylation levels of other $6 \mathrm{CG}$ sites adjacent to the targeted region in the present study (Figure 1) were analyzed, there were no significant correlations between them (data not shown).

\section{Discussion}

In the present study, there was a positive correlation between neuroticism scores and methylation levels of the BDNF gene, and higher neuroticism scores were related to higher BDNF gene methylation. This result suggests a close linkage between neuroticism and increased BDNF gene methylation and sheds some light on the biological mechanism of neuroticism as a predisposing factor for depression.

First, the increased methylation of the BDNF gene may play a major role in the formation mechanism of neuroticism.

Table I Demographic characteristics, five domain scores of the NEO PI-R and methylation levels of the BDNF gene of the subjects

\begin{tabular}{ll}
\hline Characteristics & Number \\
\hline Age, years & $22.4 \pm 0.6$ \\
Male/female, $\mathrm{n}$ & $49 / 49$ \\
$\mathrm{BMI}, \mathrm{kg} / \mathrm{m}^{2}$ & $21.0 \pm 2.5$ \\
NEO PI-R, score & \\
$\quad$ Neuroticism & $106.3 \pm 23.5$ \\
Extraversion & $99.3 \pm 21.7$ \\
Openness to experience & $115.1 \pm 15.1$ \\
Agreeableness & $108.9 \pm 18.9$ \\
Conscientiousness & $98.0 \pm 21.4$ \\
BDNF gene methylation & \\
Ist CG site & $2.13 \pm 1.50$ \\
2nd CG site & $0.20 \pm 0.54$ \\
Mean of Ist and 2nd CG sites & $1.16 \pm 0.87$ \\
\hline
\end{tabular}

Note: The figures on the table show mean $\pm S D$.

Abbreviations: BDNF, brain-derived neurotrophic factor; BMI, body mass index; NEO PI-R, NEO Personality Inventory-Revised. 
Table 2 Correlations among NEO PI-R scores, BMI and the BDNF gene methylation levels

\begin{tabular}{|c|c|c|c|c|c|c|c|c|}
\hline & $\mathbf{I}$ & 2 & 3 & 4 & 5 & 6 & 7 & 8 \\
\hline \multicolumn{9}{|l|}{ I. Neuroticism } \\
\hline 2. Extraversion & -0.372 & & & & & & & \\
\hline 3. Openness to experience & 0.046 & $0.312^{* *}$ & & & & & & \\
\hline 4. Agreeableness & $-0.326 * *$ & 0.021 & 0.074 & & & & & \\
\hline 5. Conscientiousness & $-0.448 * *$ & 0.420 ** & 0.169 & $0.315^{* *}$ & & & & \\
\hline 6. BMI & 0.075 & $-0.204^{*}$ & $-0.205^{*}$ & -0.165 & -0.286 & & & \\
\hline 7. Methylation of Ist CG site & $0.230 *$ & -0.069 & 0.149 & 0.132 & -0.011 & -0.044 & & \\
\hline 8. Methylation of 2 nd CG site & -0.151 & 0.048 & 0.026 & 0.031 & 0.118 & -0.097 & $0.295^{* *}$ & \\
\hline 9. Mean of Ist and 2 nd CG sites & 0.150 & -0.042 & 0.137 & 0.126 & 0.047 & -0.068 & $0.956^{* *}$ & $0.562 * *$ \\
\hline
\end{tabular}

Notes: The figures on the table show Pearson's correlation coefficients. $* p<0.05, * * p<0.01$.

Abbreviations: BDNF, brain-derived neurotrophic factor; BMI, body mass index; NEO PI-R, NEO Personality Inventory-Revised.

Twin studies show that about $40 \%$ of the variability in neuroticism is attributed to genetic factors and the rest to environmental factors. ${ }^{21}$ In line with this, our previous study suggests that a dysfunctional parenting style induces increased neuroticism. ${ }^{22}$ On the other hand, it is shown that

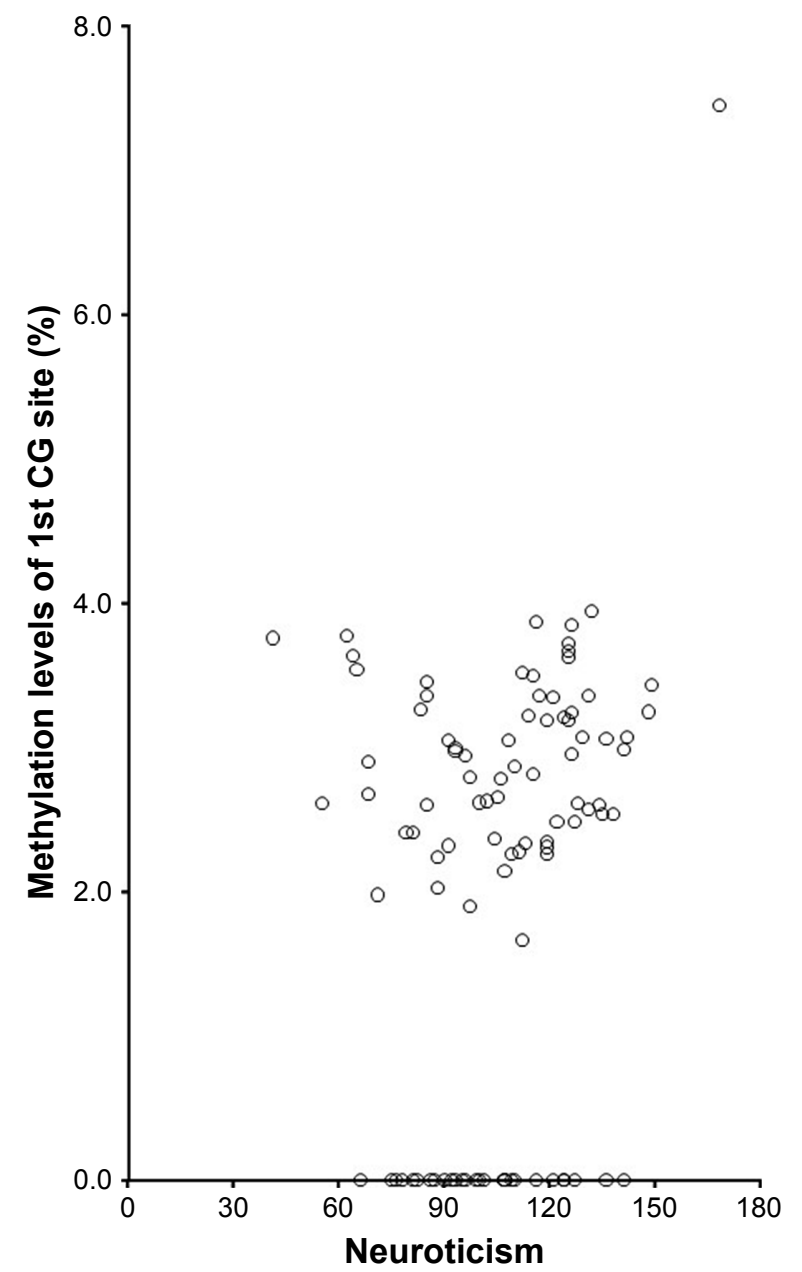

Figure 2 Relationship between neuroticism and methylation levels of the Ist CG site of the BDNF gene.

Abbreviation: BDNF, brain-derived neurotrophic factor. caregiver maltreatment induces increased BDNF gene methylation in prefrontal cortex, amygdala and hippocampus of rats. ${ }^{23}$ In addition, individuals who received childhood abuse or low maternal care show increases in BDNF gene methylation in lymphocytes. ${ }^{24,25}$ These studies on the epigenetics of BDNF and our present study collectively suggest that high neuroticism is at least partly ascribable to increased BDNF gene methylation resulting from negative experiences in early life. Incidentally, there is a possibility that this association is mediated by reduced hippocampal volume, a putative neuroanatomical basis of high neuroticism. ${ }^{26}$

Second, further increases in methylation of the BDNF gene resulting from high neuroticism may be implicated in the process from high neuroticism to the onset of depression. It is demonstrated that individuals high in neuroticism are likely to experience stressful life events. ${ }^{27}$ On the other hand, negative life events are shown to induce within-subject increases in neuroticism. ${ }^{28}$ Here, a vicious circle may be formed between stress and neuroticism. This vicious circle may lead to marked increases in BDNF gene methylation and decreased blood levels of BDNF observed in depressed patients. ${ }^{6,8}$ It is noteworthy that one study suggests that an interaction between altered BDNF function by the Val66Met genotype and neuroticism levels predicts future life stressors. ${ }^{29}$ This study at least partly supports our contention that there is a vicious circle among altered BDNF function by methylation, neuroticism and stress.

Finally, in the present study, extraversion, openness to experience, agreeableness and conscientiousness were not associated with methylation of the BDNF gene. This result appears to be reasonable, since there is no or weak evidence that these personality traits are independent predictors of depression. ${ }^{10,12}$

The present study has several limitations. First, methylation status of a neutral control gene was not analyzed. 
Table 3 Effects of NEO PI-R scores and sex on methylation levels of the BDNF gene

\begin{tabular}{|c|c|c|c|c|c|}
\hline & \multirow[t]{3}{*}{ Male } & \multirow[t]{3}{*}{ Female } & \multicolumn{3}{|l|}{$F$ value } \\
\hline & & & NEO & Sex & NEO \\
\hline & & & PI-R & & PI-R $\times$ sex \\
\hline \multicolumn{6}{|l|}{ Ist CG site, low vs high } \\
\hline Neuroticism & $1.68 \pm 1.58$ vs $2.47 \pm 1.31$ & $1.75 \pm 1.34$ vs $2.63 \pm 1.64$ & $8.125^{* *}$ & 0.007 & 0.009 \\
\hline Extraversion & $\mathrm{I} .95 \pm \mathrm{I} .52$ vs $2.3 \mathrm{I} \pm \mathrm{I} .42$ & $2.52 \pm 1.70$ vs $1.89 \pm 1.38$ & 0.244 & 0.003 & 2.579 \\
\hline Openness to experience & $\mathrm{I} .70 \pm \mathrm{I} .54$ vs $2.54 \pm \mathrm{I} .30$ & $2.16 \pm 1.78$ vs $2.17 \pm 1.31$ & 1.808 & 0.002 & 1.874 \\
\hline Agreeableness & $\mathrm{I} .90 \pm \mathrm{I} .45$ vs $2.38 \pm \mathrm{I} .5 \mathrm{I}$ & $2.17 \pm 1.87$ vs $2.16 \pm 1.31$ & 0.585 & 0.010 & 0.596 \\
\hline Conscientiousness & $2.03 \pm 1.45$ vs $2.20 \pm 1.55$ & $2.37 \pm 1.33$ vs $2.02 \pm 1.68$ & 0.115 & 0.007 & 0.652 \\
\hline \multicolumn{6}{|l|}{ 2nd CG site, low vs high } \\
\hline Neuroticism & $0.22 \pm 0.59$ vs $0.14 \pm 0.49$ & $0.22 \pm 0.52$ vs $0.22 \pm 0.60$ & 0.066 & 0.001 & 0.103 \\
\hline Extraversion & $0.12 \pm 0.46$ vs $0.26 \pm 0.63$ & $0.24 \pm 0.62$ vs $0.21 \pm 0.52$ & 0.101 & 0.001 & 0.565 \\
\hline Openness to experience & $0.14 \pm 0.49$ vs $0.22 \pm 0.59$ & $0.19 \pm 0.52$ vs $0.25 \pm 0.59$ & 0.252 & 0.001 & 0.015 \\
\hline Agreeableness & $0.12 \pm 0.45$ vs $0.26 \pm 0.64$ & $0.24 \pm 0.58$ vs $0.21 \pm 0.55$ & 0.293 & 0.007 & 0.524 \\
\hline Conscientiousness & $0.1 \mathrm{I} \pm 0.42$ vs $0.28 \pm 0.67$ & $0.26 \pm 0.64$ vs $0.20 \pm 0.50$ & 0.09 & 0.000 & 0.982 \\
\hline \multicolumn{6}{|c|}{ Mean of Ist and 2nd CG site, low vs high } \\
\hline Neuroticism & $0.95 \pm 0.95$ vs $1.30 \pm 0.75$ & $0.98 \pm 0.79$ vs $1.42 \pm 0.93$ & $5.509 *$ & 0.003 & 0.026 \\
\hline Extraversion & $\mathrm{I} .03 \pm 0.86$ vs $\mathrm{I} .28 \pm 0.87$ & $1.37 \pm 0.94$ vs $1.05 \pm 0.82$ & 0.095 & 0.000 & 2.574 \\
\hline Openness to experience & $0.92 \pm 0.88$ vs $1.38 \pm 0.78$ & I. $17 \pm 0.97$ vs $1.20 \pm 0.80$ & 1.747 & 0.000 & 1.522 \\
\hline Agreeableness & $1.01 \pm 0.82$ vs $1.32 \pm 0.91$ & $1.19 \pm 1.04$ vs $1.18 \pm 0.76$ & 0.715 & 0.020 & 0.790 \\
\hline Conscientiousness & $\mathrm{I} .07 \pm 0.8 \mathrm{I}$ vs $\mathrm{I} .24 \pm 0.95$ & $1.30 \pm 0.84$ vs $|| I \pm 0.9 \mid$. & 0.038 & 0.002 & 0.989 \\
\hline
\end{tabular}

Notes: The figures on the table show mean \pm SD of methylation levels of the BDNF gene. $* p<0.05, * * p<0.01$.

Abbreviations: BDNF, brain derived neurotrophic factor; NEO PI-R, NEO Personality Inventory-Revised.

A

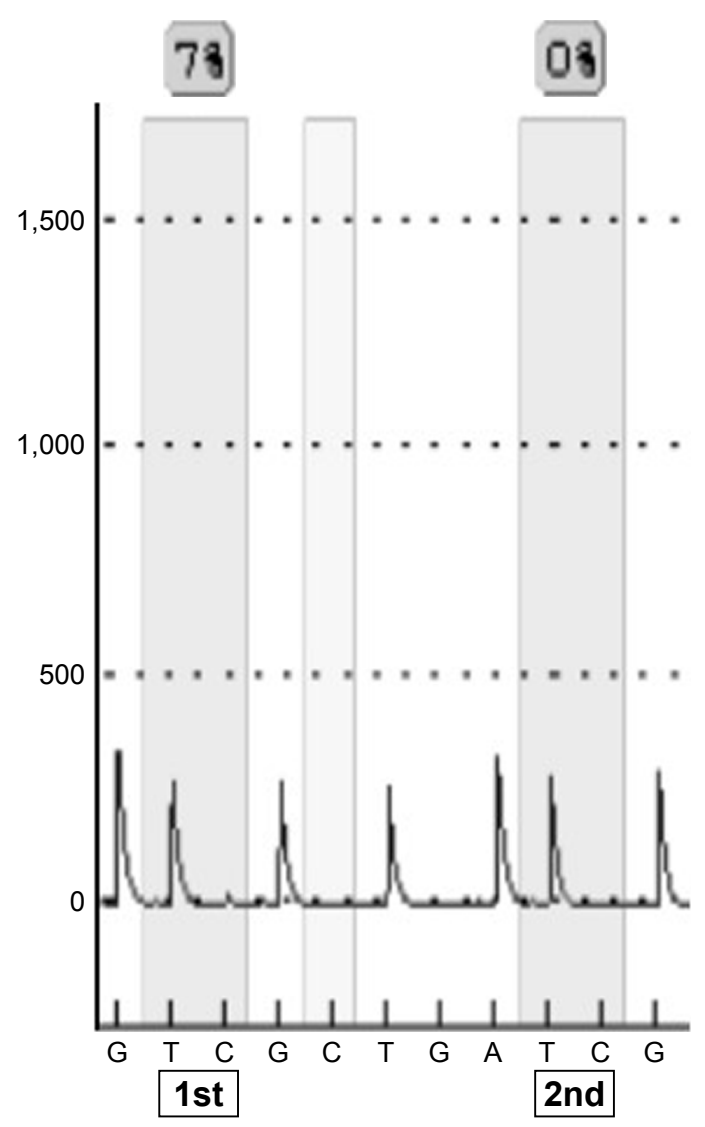

B Individual with low neuroticism

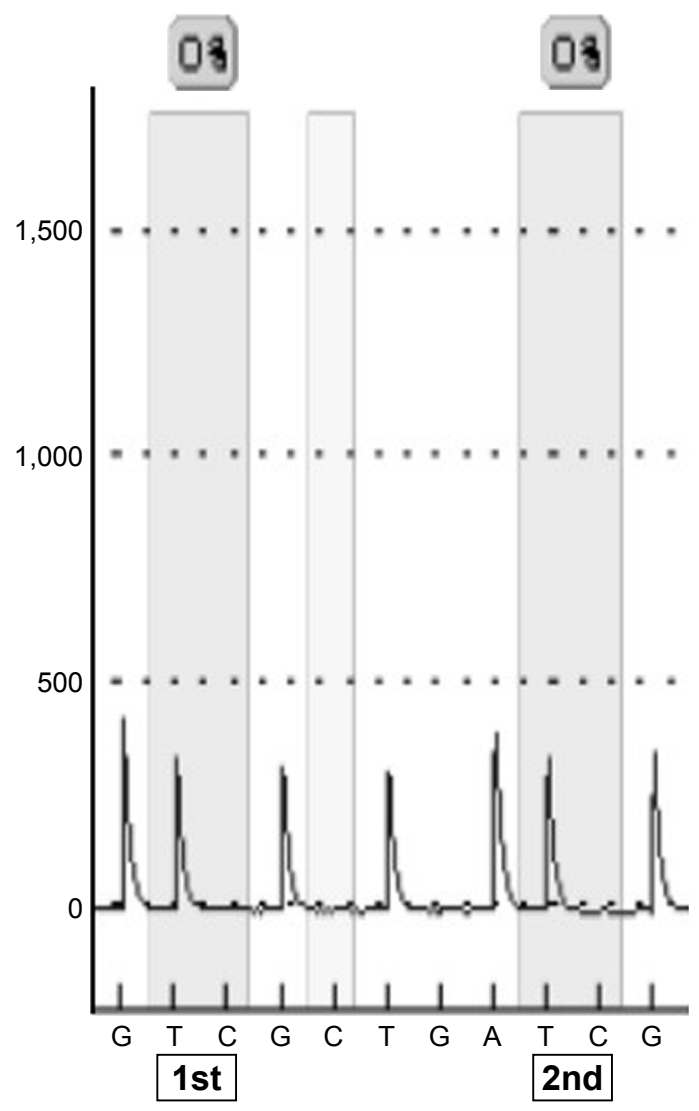

Figure 3 Pyrograms of representative individuals with high $(\mathbf{A})$ and low $(\mathbf{B})$ neuroticism scores.

Notes: The percentages of methylation in the highlighted regions are estimated by the ratio of $C$ and $T$ intensities. Ist and 2 nd show the Ist and 2 nd $C G$ site within the examined region of the BDNF gene, respectively.

Abbreviation: BDNF, brain derived neurotrophic factor. 
Thus, the possibility that the association between neuroticism and BDNF gene methylation observed was due to genomewide effects rather than a BDNF-specific effect cannot be excluded. Second, our subjects had a homogeneous and rather specific background, ie, they were all young and well-educated Japanese. Therefore, it may be difficult to extrapolate the present results to general populations or other ethnic groups. Third, the number of subjects was relatively small, suggesting lack of a statistical power to detect small differences. Fourth, blood BDNF levels were not analyzed in the present study. Thus, replication studies in larger populations with other backgrounds and with data for blood BDNF levels are needed to confirm the present results.

\section{Conclusion}

The present study suggests that higher neuroticism is related to increased methylation of the BDNF gene.

\section{Acknowledgments}

This study was supported by funding from the Ministry of Education, Culture, Sports, Science and Technology of Japan. The funding had no effect on the present study.

\section{Disclosure}

The authors report no conflicts of interest in this work.

\section{References}

1. Goldberg AD, Allis CD, Bernstein E. Epigenetics: a landscape takes shape. Cell. 2007;128(4):635-638.

2. Mohn F, Weber M, Rebhan M, et al. Lineage-specific polycomb targets and de novo DNA methylation define restriction and potential of neuronal progenitors. Mol Cell. 2008;30(6):755-766.

3. Egan MF, Kojima M, Callicott JH, et al. The BDNF val66met polymorphism affects activity-dependent secretion of BDNF and human memory and hippocampal function. Cell. 2003;112(2):257-269.

4. Chen ZY, Jing D, Bath KG, et al. Genetic variant BDNF (Val66Met) polymorphism alters anxiety related behavior. Science. 2006;314(5796): 140-143.

5. Bueller JA, Aftab M, Sen S, Gomez-Hassan D, Burmeister M, Zubieta JK. BDNF Val66Met allele is associated with reduced hippocampal volume in healthy subjects. Biol Psychiatry. 2006;59(9):812-815.

6. Molendijk ML, Bus BA, Spinhoven P, et al. Serum levels of brainderived neurotrophic factor in major depressive disorder: state-trait issues, clinical features and pharmacological treatment. Mol Psychiatry. 2011;16(11):1088-1095.

7. Martinowich K, Hattori D, Wu H, et al. DNA methylation-related chromatin remodeling in activity-dependent BDNF gene regulation. Science. 2003;302(5646):890-893.

8. Chen D, Meng L, Pei F, Zheng Y, Leng J. A review of DNA methylation in depression. J Clin Neurosci. 2017;43:39-46.

9. Costa PT Jr, McCrae RR. Revised NEO Personality Inventory (NEO$P I-R)$ and NEO Five-Factor Inventory (NEO-FFI) Professional Manual. North Florida: Psychological Assessment Resources; 1992.
10. Klein DN, Kotov R, Bufferd SJ. Personality and depression: explanatory models and review of the evidence. Annu Rev Clin Psychol. 2011; 7:269-295.

11. Ormel J, Jeronimus BF, Kotov R, et al. Neuroticism and common mental disorders: meaning and utility of a complex relationship. Clin Psychol Rev. 2013;33(5):686-697.

12. Kendler KS, Gatz M, Gardner CO, Pedersen NL. Personality and major depression: a Swedish longitudinal, population-based twin study. Arch Gen Psychiatry. 2006;63(10):1113-1120.

13. Suzuki A, Matsumoto Y, Shibuya N, et al. The brain-derived neurotrophic factor Val66Met polymorphism modulates the effects of parental rearing on personality traits in healthy subjects. Genes Brain Behav. 2011;10(4):385-391.

14. Terracciano A, Lobina M, Piras MG, et al. Neuroticism, depressive symptoms, and serum BDNF. Psychosom Med. 2011;73(8):638-642.

15. American Psychiatric Association. Diagnostic and Statistical Manual of Mental Disorders. 4th ed. Washington, DC: American Psychiatric Association; 1994.

16. Keleshian VL, Modi HR, Rapoport SI, Rao JS. Aging is associated with altered inflammatory, arachidonic acid cascade, and synaptic markers, influenced by epigenetic modifications, in the human frontal cortex. J Neurochem. 2013;125(1):63-73.

17. McCrae RR, Terracciano A. Personality Profiles of Cultures Project. Universal features of personality traits from the observer's perspective: data from 50 cultures. J Pers Soc Psychol. 2005;88(3):547-561.

18. Shimonaka Y, Nakazato K, Gondo Y, et al. NEO-PI-R, NEO-FFI Manual for the Japanese Version. Tokyo: Tokyo Shinri; 1999.

19. Kundakovic M, Gudsnuk K, Herbstman JB, Tang D, Perera FP, Champagne FA. DNA methylation of BDNF as a biomarker of earlylife adversity. Proc Natl Acad Sci U S A. 2015;112(22):6807-6813.

20. Suzuki A, Kamata M, Matsumoto Y, Shibuya N, Otani K. Increased body mass index associated with increased harm avoidance and decreased self-directedness in Japanese women. J Nerv Ment Dis. 2009; 197(3):199-201.

21. Cervone DC, Pervin LA. Trait Theory: The Five-Factor Model; Applications and Evaluation of Trait Approaches to Personality, in: Personality: Theory and Research. 12th ed. Hoboken: John Wiley \& Sons; 2013.

22. Takahashi N, Suzuki A, Matsumoto Y, Shirata T, Otani K. Perceived parental affectionless control is associated with high neuroticism. Neuropsychiatr Dis Treat. 2017;13:1111-1114.

23. Roth TL, Lubin FD, Funk AJ, Sweatt JD. Lasting epigenetic influence of early-life adversity on the BDNF gene. Biol Psychiatry. 2009;65(9): 760-769.

24. Thaler L, Gauvin L, Joober R, et al. Methylation of BDNF in women with bulimic eating syndromes: associations with childhood abuse and borderline personality disorder. Prog Neuropsychopharmacol Biol Psychiatry. 2014;54:43-49.

25. Unternaehrer E, Meyer AH, Burkhardt SC, et al. Childhood maternal care is associated with DNA methylation of the genes for brain-derived neurotrophic factor (BDNF) and oxytocin receptor (OXTR) in peripheral blood cells in adult men and women. Stress. 2015;18(4):451-461.

26. Yamasue H, Abe O, Suga M, et al. Gender-common and -specific neuroanatomical basis of human anxiety-related traits. Cereb Cortex. 2008; $18: 46-52$.

27. Kendler KS, Gardner CO, Prescott CA. Personality and the experience of environmental adversity. Pychol Med. 2003;33(7):1193-1202.

28. Jeronimus BF, Ormel J, Aleman A, Penninx BW, Riese H. Negative and positive life events are associated with small but lasting change in neuroticism. Psychol Med. 2013;43(11):2403-2415.

29. Lehto K, Mäestu J, Kiive E, Veidebaum T, Harro J. BDNF Val66Met genotype and neuroticism predict life stress: a longitudinal study from childhood to adulthood. Eur Neuropsychopharmacol. 2016;26(3): 562-569. 


\section{Publish your work in this journal}

Neuropsychiatric Disease and Treatment is an international, peerreviewed journal of clinical therapeutics and pharmacology focusing on concise rapid reporting of clinical or pre-clinical studies on a range of neuropsychiatric and neurological disorders. This journal is indexed on PubMed Central, the 'PsycINFO' database and CAS, and is the official journal of The International Neuropsychiatric Association (INA). The manuscript management system is completely online and includes a very quick and fair peer-review system, which is all easy to use. Visit http://www.dovepress.com/testimonials.php to read real quotes from published authors.

\footnotetext{
Submit your manuscript here: http://www.dovepress.com/neuropsychiatric-disease-and-treatment-journal
} 